\title{
A simple characterization methodology for the identification of the visco-elastic behavior of thermoset adhesives during cure
}

\author{
Marion Girard*iD, Mael Péron, Alexandre Uguen, Pascal Casari and Frédéric Jacquemin
}

*Correspondence:
marion.girard@univ-nantes.fr
Institut de Recherche en
Génie Civil et Mécanique,
Université de Nantes,
GeM-E3M, UMR CNRS
6183, 58 Rue Michel Ange,
44600 Saint Nazaire, France

*Correspondence: mariongirard@univ-nantes.fr Génie Civil et Mécanique, Université de Nantes, 6183, 58 Rue Michel Ange,

\begin{abstract}
The identification of the mechanical behavior of adhesives is necessary to describe the development of residual stresses during their curing, which might impact their mechanical strength and lead to early failure of the bonding. A simple characterization and modeling approach is therefore developed and presented, which permits to monitor and identify the mechanical behavior of a thermosetting adhesive during the whole curing process. The test method is based on a compressive test, which consists in applying a periodic displacement and recording the subsequent load variations during cure. The test set-up relies on a simple apparatus as it consists in steel cylinders mounted on a standard tensile test machine. The analysis of the mechanical behavior is based on an analytical description of a visco-elastic constitutive law following the Maxwell model, leading to the identification of the material apparent viscosity and Young's modulus. This characterization methodology is applied to an epoxy adhesive during cure. The obtained mechanical properties are in good agreement with values provided by the material supplier, which permits to validate the developed methodology.
\end{abstract}

Keywords: Visco-elastic behavior, Curing, Adhesive bonding

\section{Introduction}

Structural adhesives based on thermosetting polymers see their mechanical behavior vary substantially during their processing because of their chemical nature. Indeed, the extension of the chains and the crosslinking of the polymeric network lead to significant variations of their rheological behavior and mechanical stiffness. These materials are often considered to change from an initial (elasto-visco-plastic) liquid state to a rubbery (viscoelastic) gel and finally to a vitrified glassy (elastic) state [4]. In addition, the curing reaction induces a volume reduction called chemical shrinkage [16, 26], which is due to the mobility of the polymeric chains and the creation of new chemical bonds and accompanied by a closer packing of the molecules. In the confined conditions of a bonded assembly, this volume reduction may be restrained by the presence of the substrate. As the mechanical stiffness of the adhesive increases, this shrinkage might initiate the development of residual stresses and may lead to early failure especially during subsequent thermal cycling conditions or mechanical loadings [12, 14, 18, 25, 27]. In order

(c) The Author(s) 2020. This article is licensed under a Creative Commons Attribution 4.0 International License, which permits use, sharing, adaptation, distribution and reproduction in any medium or format, as long as you give appropriate credit to the original author(s) and the source, provide a link to the Creative Commons licence, and indicate if changes were made. The images or other third party material in this article are included in the article's Creative Commons licence, unless indicated otherwise in a credit line to the material. If material is not included in the article's Creative Commons licence and your intended use is not permitted by statutory regulation or exceeds the permitted use, you will need to obtain permission directly from the copyright holder. To view a copy of this licence, visit http://creativeco mmons.org/licenses/by/4.0/. 
to predict these residual stresses and to prevent adhesive related failures, the mechanical behavior of adhesives must be well understood especially during curing in order to model and predict their mechanical response all along the process.

Such polymeric materials exhibit both elastic and viscous behavior from their initial liquid to their final solid state. Characterizing their mechanical behavior therefore requires the use of a wide characterization methodology, covering the different mechanical behaviors of the material during the whole curing process from the liquid to the solid state. During the early stages of curing and when the adhesive is still liquid, rheometer tests appear to be well adapted to the characterization of the mechanical behavior of the material $[17,21,22]$. This is due to the relatively negligible stiffness of the adhesive. These tests are however limited to the liquid state as the measured mechanical answer generally leads to an "infinite" viscosity when the adhesive begins to gelify. Once the adhesive is solid, i.e. after the gel point, several mechanical tests can be performed in order to record the behavior of the adhesive during the later stages of cure. Simple tensile tests can be run to monitor the elastic response of the material and identify its Young's modulus and Poisson's coefficient [13]. These tests are easy to develop and do not require much efforts when curing is slow and happens at room temperature, but only lead to the elastic behavior of the material. Dynamic mechanical analysis (DMA) [2, 22-24] can be performed to overpass this limitation, as the temperature and frequency can be set on a wide range. This permits to characterize the visco-elastic behavior of the material as a function of the temperature and the cure in the case of high temperature curing adhesives. It however relies on time consuming experiments and analysis to ensure correct test conditions and to identify the material properties, respectively. The use of dynamic torsion tests with a rheometer to access the same material properties is also reported $[1,8]$.

Several authors developed characterization methods based on ultrasonic waves to monitor the elastic properties of thermosetting resins during cure $[5,11]$. This method allows for an identification of the material behavior during the whole curing but it is however limited to constant temperature condition as the ultrasonic waves propagation is highly sensitive to this parameter. The use of a plunger-type dilatometer permitted to identify the evolution of the bulk modulus of a thermoset resin during cure as it was submitted to cyclic compressive solicitations $[15,19]$. Finally, the use of modified universal testing machines could also be observed in the dental restoration domain to identify the visco-elastic properties of the material during the whole curing by applying a sinusoidal pulse at regular intervals [3].

Once the material behavior has been identified, a fine modelling is required in order to predict the development of the residual stresses state of the adhesive during cure. Several models have been used in the past decades to translate the evolution of the mechanical behavior of thermosetting resins during polymerization. The simplest model $[7,19,20]$ is based on an incremental formulation of the linear elastic constitutive law, accounting for the evolution of the matrix properties during cure. Its simple formulation makes it easy to implement and to feed from properties identified experimentally. It however generally leads to an overestimation of the developed stress state as it does not account for possible stresses relaxation due to the viscoelastic material behavior. Improvements of this model were proposed, taking into account the viscous 
response of the adhesive through the use of a combination of elastic spring and viscous damper models [7]. These models are more complex to implement and the properties needed to feed the model can be more difficult to identify compared to the linear elastic model. They however lead to a more accurate description of the material behavior. The two main models used are the Maxwell and the Kelvin-Voigt model [3, 9]. The first one is more adapted for viscoelastic fluid where there is no non-zero constant load equilibrium and where chemical shrinkage can therefore not be taken into account. The second one allows for the existence of a stable and unique configuration under zero loading which is characteristic of solids, unlike fluids. Finally, complex visco-elastic models (e.g. the generalized Maxwell model) have been widely used to describe the behavior of thermosetting resins during cure $[1,2]$. They however rely on an extensive characterization campaign based on numerous DMA tests and analysis, which adds to the difficulty in the implementation of such model within a simulation framework $[6,10]$. These models however represent the most accurate description of the material behavior, accounting for possible stresses relaxation at various degrees of cure and temperatures.

From this literature review, it appears that characterizing the mechanical behavior of the adhesive from its uncured liquid state to its fully cured solid state requires the use of at least two different characterization methods and devices. Capturing its viscoelastic behavior relies on the use of specific methods (DMA, rheometer), which requires more time consuming analysis than for the elastic behavior. The use of a purely elastic model to describe the material behavior might lead to an overestimation of the residual stresses, as it does not account for possible stresses relaxation. It is however easier to implement numerically and requires less experimental characterization to feed the model. On the opposite, complex visco-elastic models are more difficult to implement, and require fastidious experimental characterization and intensive calculations for parameters identification. The success of a model depends on its ease of use, the accuracy of its predictions, and on how meaningful the material parameters are. Therefore, a good approximate solution represented by a simple model is often nearly as informative as an exact solution given by a more complex model. A good compromise between all these criteria resides in the use of a simple viscoelastic model, which could account for possible stresses relaxation without needing too much experimental nor numerical efforts.

This study therefore aims at developing a simple methodology to characterize the mechanical behavior of a bonded joint during its whole cure process. It is based on the use of a universal testing machine with a simple compressive testing set up. The material behavior is followed during the whole polymerization and is modeled thanks to a Maxwell model, which permits to reproduce the observed mechanical response. This leads to the identification of two mechanical parameters of the adhesive over time in an explicit way: its viscosity and Young's modulus. Firstly, the experimental procedure is explained. Then, the analytical Maxwell model used to fit the experimental results is presented. The identification strategy developed to obtain the evolution of the material viscosity and Young's modulus uniquely and explicitly is presented. Finally, the results obtained on a commercial epoxy resin are presented and compared with values from the manufacturer datasheet. 


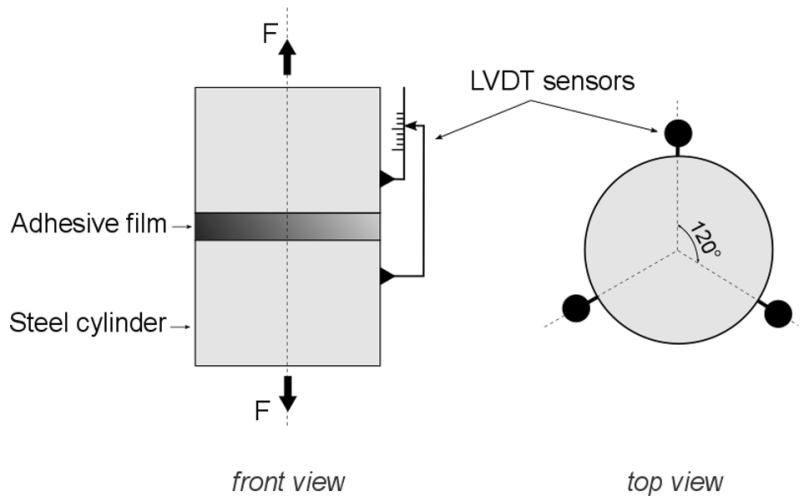

Fig. 1 Montage design

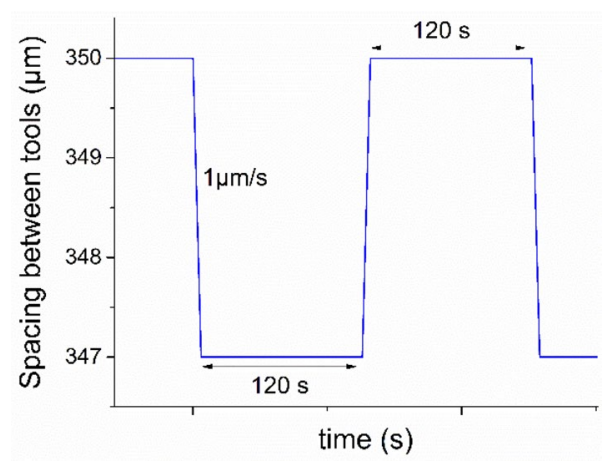

Fig. 2 Imposed cycle

\section{Materials and methods}

\section{Experimental procedure}

The commercial adhesive studied is a two components epoxy resin named Epolam 2001/95B from AXSON supplier. The two components are mixed together in stoichiometric ratios and degassed under vacuum $\left(10^{-4} \mathrm{~Pa}\right)$ during $2 \mathrm{~min}$. The mixture is then placed between two S235 steel cylinders with $50 \mathrm{~mm}$ diameter and $50 \mathrm{~mm}$ height as shown in Fig. 1. The thickness of the thermoset liquid adhesive is set to $350 \mu \mathrm{m}( \pm 50 \mu \mathrm{m})$.

The assembly is positioned in a tensile test machine (ZWICK-ROELL Z050). A displacement control is imposed, which provides a periodic loading-unloading cycle. In addition, three displacement sensors (LVDT, for Linear Variable Differential Transformer) are placed around the sample at $120^{\circ}$ from one another to measure the local displacement between the two steel plates (as shown in Fig. 1). This setup allows to get both the stiffness of the assembly and the machine, which has to be taken into account. Experiments were carried out at room temperature $\left(20^{\circ} \mathrm{C} \pm 0.5^{\circ} \mathrm{C}\right)$.

The displacement of the moving crosshead shown in Fig 2 is imposed as a quasirectangular signal applied every $4 \mathrm{~min}$, with a $3 \mu \mathrm{m}$ amplitude at a rate of $1 \mu \mathrm{m} / \mathrm{s}$. The maximum amplitude selected corresponds to less than $1 \%$ of the joint deformation to ensure that the material behavior of curing adhesive could be studied by means of 
the theory of linear viscoelasticity [9]. The cycle has been designed to have a first part with a constant deformation rate in order to have a visco-elastic contribution, and a part with constant deformation to study the relaxation of the bonded joint and to quantify the viscous contribution. The beginning of the mechanical stress is applied 10 min after mixing of the adhesive, allowing to set the system in place. The load-displacement response of the whole assembly is recorded. This permits to interrogate regularly the mechanical behavior of the adhesive film.

\section{Model}

To exploit and analyze the obtained results, a Maxwell rheological model illustrated in Fig. 3, which is suited for a viscoelastic fluid [9], is established in series with a spring representing the stiffness of the machine (i.e. the crossheads, holding jaw and the load cell). With the Maxwell model, the adhesive is modelled with an elastic (stiffness $k_{a}$ ) and a viscous portion (damper $H_{a}$, viscosity $\eta_{a}$ ) in series.

The total displacement (i.e. the crosshead displacement), denoted $\Delta l_{t}$, is the sum of an elastic displacement from the tensile machine, $\Delta l_{m}^{e}$, an elastic displacement $\Delta l_{a}^{e}$ and a viscous displacement $\Delta l_{a}^{v}$ both from the adhesive joint (Eq. (1)).

$$
\Delta l_{t}=\Delta l_{m}^{e}+\Delta l_{a}^{e}+\Delta l_{a}^{v}
$$

\section{Hypotheses and notations}

Several hypotheses and notations are defined here, which are necessary for the development of the model. First, the stiffness of the machine, denoted $k_{m}$, is constant and known. It is deduced from the comparison of the LVDT measurement and the displacement sensor of the machine. The temperature is considered as homogeneous and constant in the system. The load cycles are sufficiently fast compared to the stiffness and

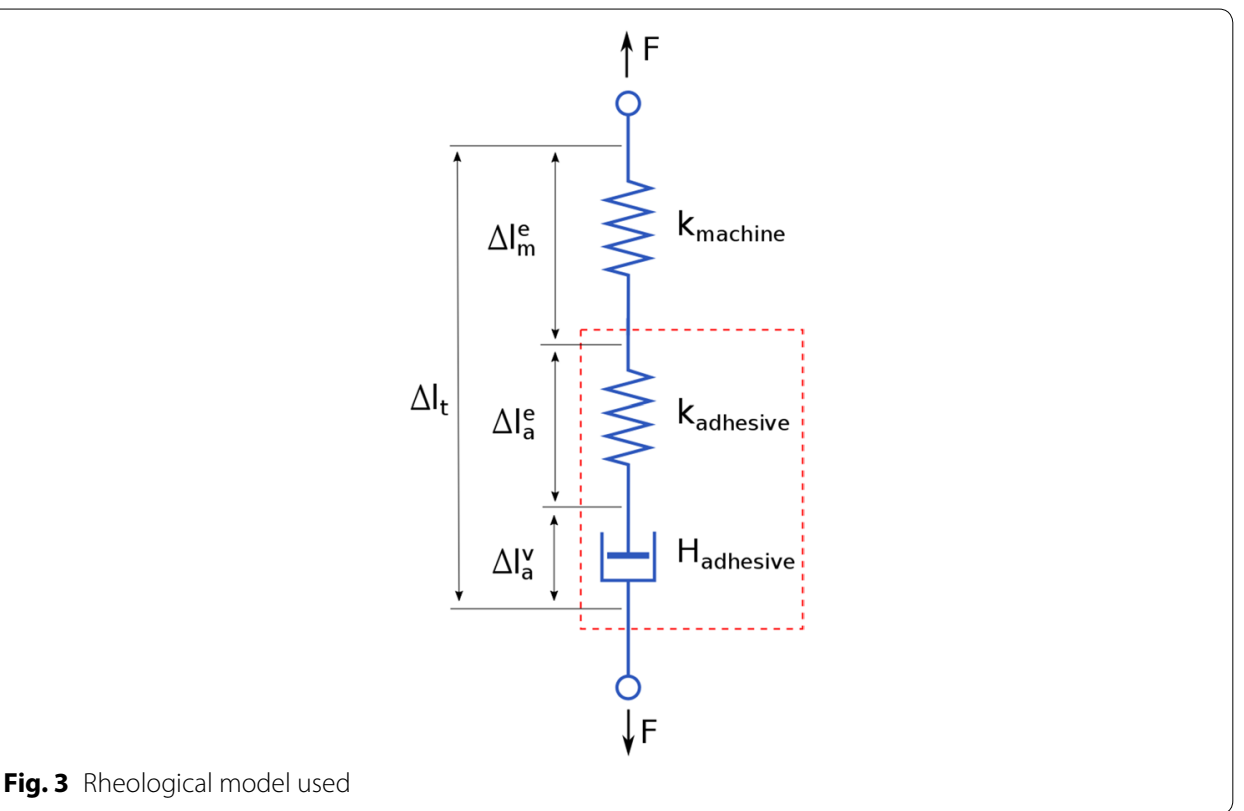


viscosity variations of the resin $\left(E_{a}(t)\right.$ and $\left.\eta_{a}(t)\right)$. This means that during each cycle, their derivatives with time are considered as null: $\dot{E}_{a}(t)=\dot{\eta}_{a}(t)=0$. The bonding surface and thickness, denoted respectively $S_{a}$ and $l_{a}$, are considered constant during the whole curing process. Finally, we define the stiffness of the adhesive as $k_{a}=E_{a} \times \frac{S_{a}}{l_{a}}$, and $\mathrm{H}_{a}=\eta_{a} \times \frac{S_{a}}{l_{a}}$.

The loading cycle is defined with the 4 segments, $0-1,1-2,2-3$ and $3-4$, shown in Fig. 4. The displacement velocity $\dot{\Delta} l_{t}$ is constant on all moving segments. Each cycle can be divided into two comparable half cycles: $\{0-1 ; 1-2\}$ and $\{2-3 ; 3-4\}$ with $\dot{\Delta} l_{t}(0-1)=-\dot{\Delta} l_{t}(2-3) . F_{0}, F_{1}, F_{2}, F_{3}$, and $F_{4}$, are the forces measured at points $0,1,2,3$ and 4 respectively.

\section{Mechanical behavior of the machine}

The behavior of the machine is assumed to remain elastic and linear with a stiffness $k_{m}$. The applied load $F$ and the displacement $\Delta l_{m}^{e}$ of the machine follow the Eq. (2):

$$
F=k_{m} \times \Delta l_{m}^{e}
$$

\section{Elastic behavior of the adhesive}

The link between the longitudinal stress in the adhesive along the bonding axis, denoted $\sigma_{a}$, and the longitudinal elastic strain, $\varepsilon_{a}^{e}$, is established with the Hooke's law by the apparent Young's modulus (Eq. 3).

$$
\sigma_{a}=E_{a} \times \varepsilon_{a}^{e}
$$

Equations (4) and (5) are then easily deduced, taking into account nominal strain and stress, showing the link between the elastic displacement $\Delta l_{a}^{e}$ in the adhesive and the load $F$.

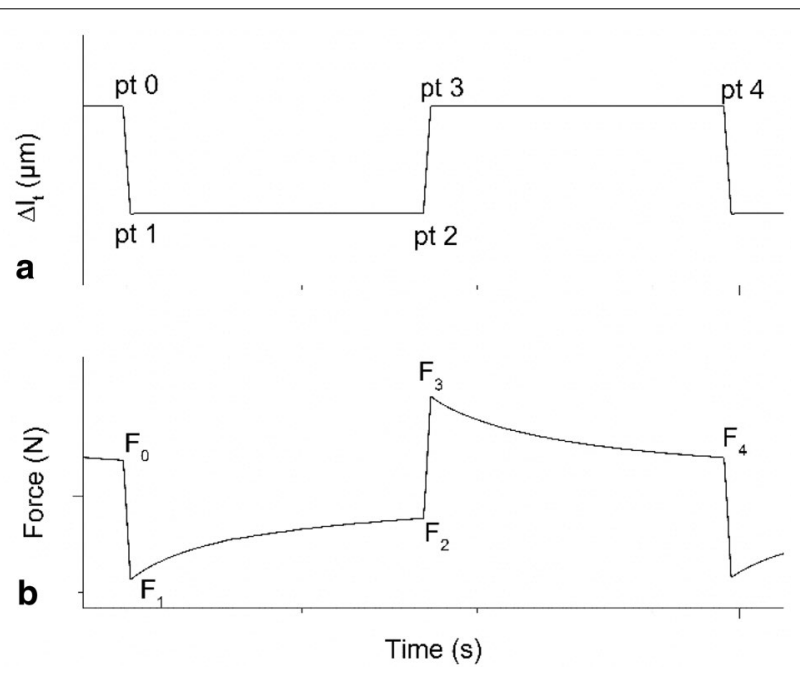

Fig. 4 One loading-unloading cycle: a imposed displacement; b measured force 


$$
\begin{aligned}
& \frac{F}{S_{a}}=E_{a} \times \frac{\Delta l_{a}^{e}}{l_{a}} \\
& \Delta l_{a}^{e}=\frac{F}{E_{a} \times \frac{S_{a}}{l_{a}}}=\frac{F}{k_{a}}
\end{aligned}
$$

\section{Viscous behavior of the adhesive}

The connection between the longitudinal stress of the bonding in the following bonding axis and the speed of longitudinal viscous strain $\dot{\varepsilon}_{a}^{v}$, is defined by the Eq. (6):

$$
\sigma_{a}=\dot{\varepsilon}_{a}^{v} \times \eta_{a}
$$

It leads to Eq. (7) and the link between the viscous displacement velocity $\Delta l_{a}^{v}$ in the adhesive and the load $F$ Eq. (8).

$$
\begin{aligned}
& \frac{F}{S_{a}}=\frac{\Delta \dot{l}_{a}^{v}}{l_{a}} \times \eta_{a} \\
& \Delta \dot{l}_{a}^{v}=\frac{F}{\eta_{a} \times \frac{S_{a}}{l_{a}}}=\frac{F}{\mathrm{H}_{a}}
\end{aligned}
$$

\section{Behavior law of the system}

From the general Eq. (1) and the equations describing the behavior of each part (Eqs. (2) (5) and (8)), we obtain the Eqs. (9) and (10):

$$
\begin{aligned}
& \Delta \dot{l}_{t}=\Delta \dot{l}_{m}^{e}+\Delta \dot{l}_{a}^{e}+\Delta \dot{l}_{a}^{v} \\
& \Delta \dot{l}_{t}=\frac{\dot{F}}{k_{m}}+\frac{\dot{F}}{k_{a}}+\frac{F}{H_{a}}
\end{aligned}
$$

By defining $k_{e q}=\frac{1}{\frac{1}{k_{m}}+\frac{1}{k_{a}}}$ and $\lambda=\frac{H}{k_{e q}}$, Eq. (10) becomes:

$$
H_{\mathrm{a}} \times \Delta \dot{l}_{t}=\lambda \dot{F}+F
$$

The differential Eq. (11) makes it possible to describe the complete behavior of the studied system.

\section{Resolution of the differential equation}

The analytical resolution of the differential equation on the different segments of a half cycle of loading, and the examination of the load values at the various points concerned permit to identify the two sought parameters $E_{a}$ and $\eta_{a}$ for each solicitation cycle.

For $t_{0} \leq t \leq t_{1}$, resolution of the differential Eq. (11), with the boundary condition $\mathrm{F}\left(\mathrm{t}=\mathrm{t}_{0}\right)=\mathrm{F}_{0}$, gives Eq. (12): 


$$
\mathrm{F}(\mathrm{t})=\mathrm{H}_{\mathrm{a}} \times \dot{\Delta} l_{t}+\left(\mathrm{F}_{0}-\mathrm{H}_{\mathrm{a}} \times \dot{\Delta} l_{t}\right) \times \exp \left(-\frac{\mathrm{t}-\mathrm{t}_{0}}{\lambda}\right)
$$

where $\dot{\Delta} l_{t}$ is a known non-zero constant.

Applying the second unused boundary condition, $\mathrm{F}\left(\mathrm{t}=\mathrm{t}_{1}\right)=\mathrm{F}_{1}$, yields the Eq. (13):

$$
\mathrm{F}\left(t=t_{1}\right)=\mathrm{H}_{a} \times \dot{\Delta} l_{t}+\left(\mathrm{F}_{0}-\mathrm{H}_{a} \times \dot{\Delta} l_{t}\right) \times \exp \left(-\frac{t_{1}-t_{0}}{\lambda}\right)=\mathrm{F}_{1}
$$

For $t_{1} \leq t \leq t_{2}$, resolution of the differential Eq. (11), with the boundary condition $\mathrm{F}\left(\mathrm{t}=\mathrm{t}_{1}\right)=\mathrm{F}_{1}$, gives Eq. (14):

$$
F(t)=F_{1} \times \exp \left(-\frac{t-t_{1}}{\lambda}\right)
$$

Applying the second unused boundary condition, $\mathrm{F}\left(\mathrm{t}=\mathrm{t}_{2}\right)=\mathrm{F}_{2}$, yields the Eq. (15):

$$
F\left(t=t_{2}\right)=F_{1} \times \exp \left(-\frac{\mathrm{t}_{2}-\mathrm{t}_{1}}{\lambda}\right)=F_{2}
$$

The resolution of the system composed of the Eqs. (13) and (15) makes it possible to express $\lambda$ and $\mathrm{H}_{a}$ according to the data of the problem express in the system Eq. (16):

$$
\left\{\begin{array}{l}
\lambda=-\frac{t_{2}-t_{1}}{\ln \left(\frac{F_{2}}{F_{1}}\right)} \\
\mathrm{H}_{a}=\frac{1}{\dot{\Delta} l_{t}} \times \frac{F_{1}-F_{0} \exp \left(-\frac{t_{1}-t_{0}}{\lambda}\right)}{1-\exp \left(-\frac{t_{1}-t_{0}}{\lambda}\right)}
\end{array}\right.
$$

The resolution of the differential equation on segments $2-3$ and 3-4 is identical.

\section{Results and discussions}

The mechanical response of the epoxy adhesive is presented in Fig. 5. The baseline of the force, corresponding to the end of the plate relaxation at the nominal joint thickness, i.e. $350 \mu \mathrm{m}$, and therefore to the points 0 and 4, is also represented in Fig. 5 as a red line. Its value remains null during the early moments of the cure, from $t=0$ to $t=5 \mathrm{~h}$. Its value then rises from $t=5 \mathrm{~h}$ to the end of the experiment. This indicates a longitudinal tensile stress though the thickness of the bonded joint. This phenomena is due to the chemical shrinkage of the adhesive. Indeed, once the adhesive stiffness starts to increase, it is capable of transmitting loads and stresses to the substrates. As the adhesive tends to shrink, its strains are blocked by the substrates and lead to a tensile stress state along the bonding direction.

Figure 6 shows some enlargements of the previous curve after different test durations. The adhesive presents 3 types of mechanical behavior according to the cure time. In the first part of the test (Fig. 6a), its mechanical response highly rises during the steps $(0-1)$ and $(2-3)$ and is due to the imposed strain rate. The obtained load then rapidly decrease and tend to a null value during the constant displacement steps (1-2) and (3-4). This is linked with the viscous behavior of the adhesive, and the adhesive seems to be purely viscous during these early steps. Then, during the following steps (Fig. 6b, c) the viscous relaxation lasts longer and continues during 


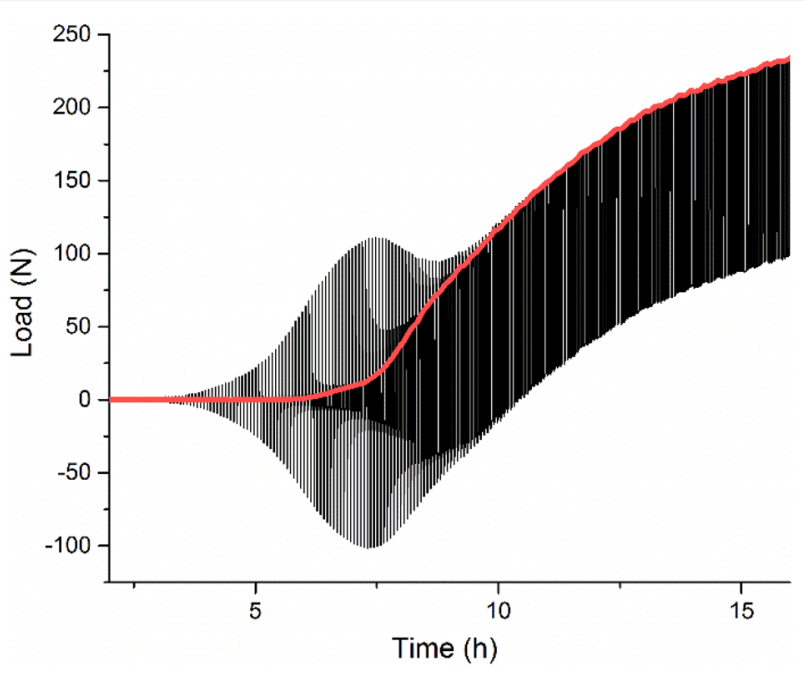

Fig. 5 Load evolution during the test
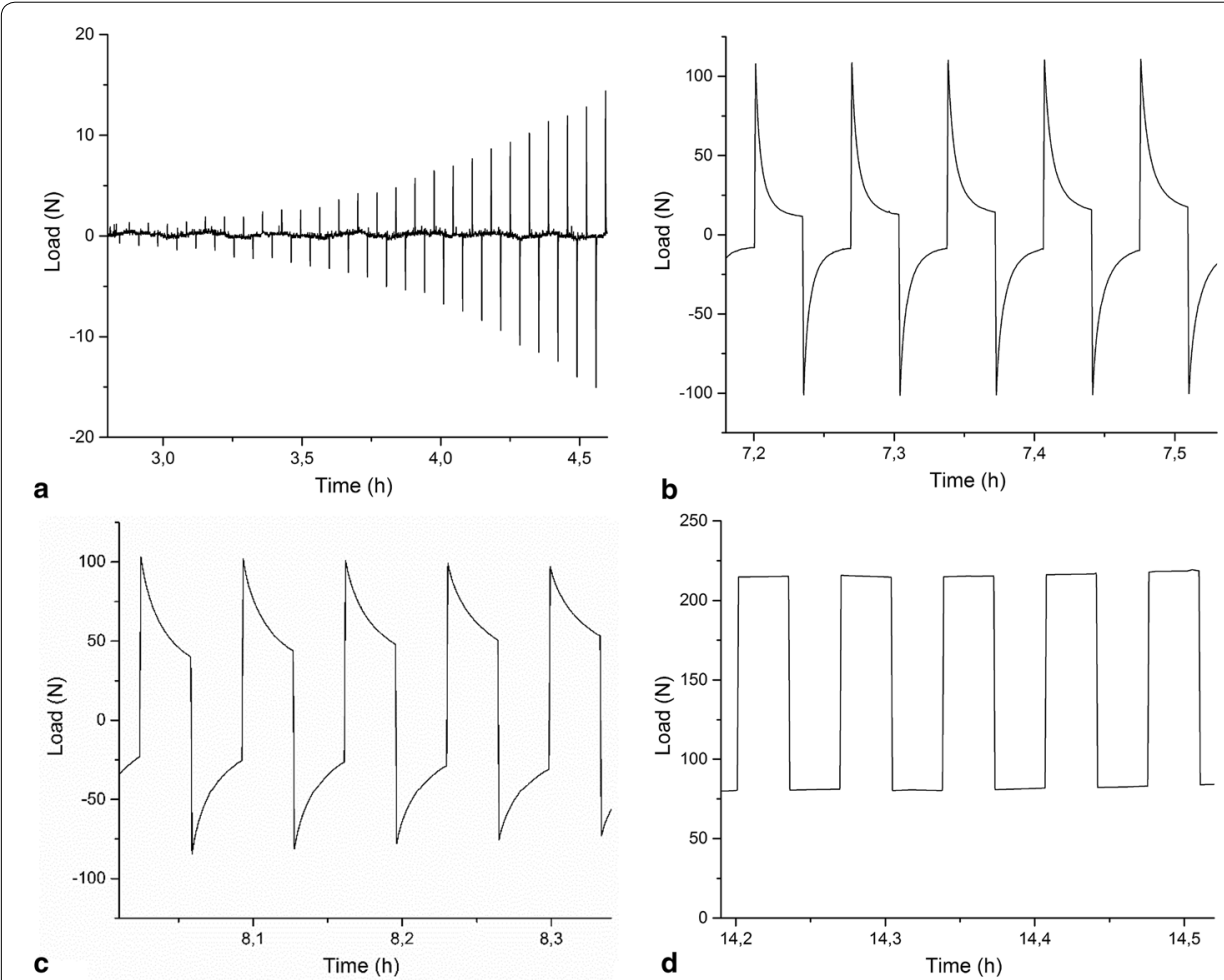

Fig. 6 Load versus time curves after 4 different test durations

the constant displacement steps (1-2) and (3-4). This translates a rise in the material viscosity due to the polymerization process. Also, the load does not return to a null value during the constant displacement steps, which is attributed to the development of the elastic stiffness of the adhesive. The material behavior therefore tends to a visco-elastic behavior with an elastic over viscous ratio increasing with time. 
During the last steps (Fig. 6d), the viscous relaxation is not visible anymore during the constant displacement steps, and the load variations are directly proportional to the imposed displacement. This translates a purely elastic behavior.

From the previous equations (Eqs. 12, 14, 16) and the load variations measured at some characteristic points defined in Fig. 4, it is possible to calculate the force evolution over time. The results from the identified model and the experimental ones for some representative cycles at $5 \mathrm{~h}, 6 \mathrm{~h}, 7 \mathrm{~h}, 8 \mathrm{~h}, 9 \mathrm{~h}$ and $10 \mathrm{~h}$ after implementing adhesive are represented in Fig. 7. An over-evaluation of the viscosity is observed for the lower times (i.e. 5, 6 and $7 \mathrm{~h}$ ) as the load relaxation happens faster experimentally than with the model. An improvement of the analytical identification methodology could however permit to better fit the experimental results.
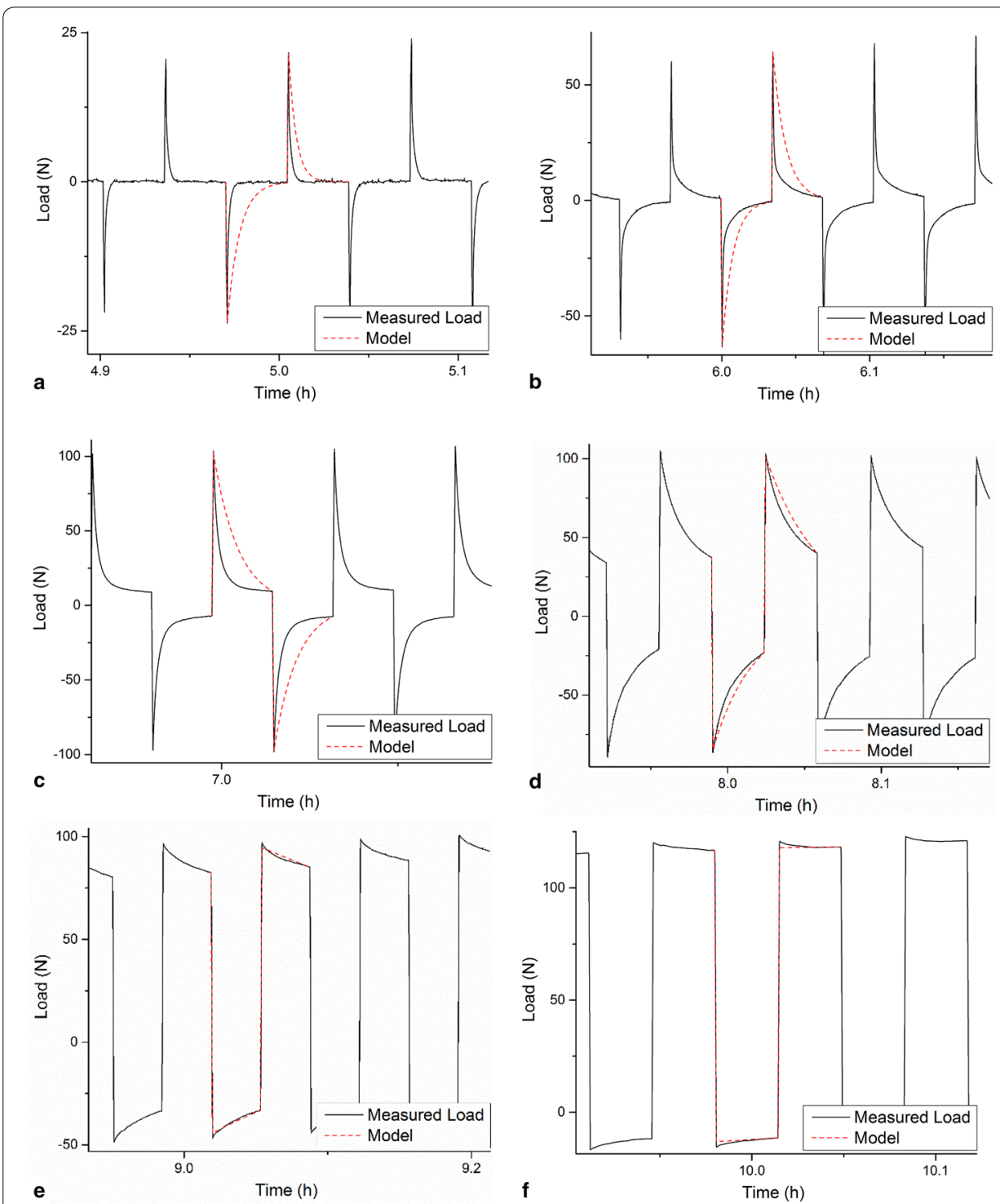

Fig. 7 Experimental results and model comparison for different times: $\mathbf{a}$ at 5 h; $\mathbf{b}$ at 6 h; $\mathbf{c}$ at $7 \mathrm{~h} ; \mathbf{d}$ at 8 h; e at $9 \mathrm{~h}$ and $\mathbf{f}$ at $10 \mathrm{~h}$ 
Expressions of $\eta_{a}$ and $E_{a}$ according to parameters $\lambda$ and $\mathrm{H}_{a}$ are defined below from previous equation:

$$
\left\{\begin{array}{l}
\eta_{a}=\mathrm{H}_{a} \times \frac{l_{a}}{S_{a}} \\
E_{a}=\frac{l_{a}}{S_{a}} \times \frac{1}{\frac{\lambda}{\mathrm{H}_{a}}-\frac{1}{k_{m}}}
\end{array}\right.
$$

After measuring the characteristic load for each cycle, it is possible to calculate $\eta_{a}$ and $E_{a}$ from Eqs. 16 and 17. The obtained values are represented in Fig. 8 as a function of $t_{0}$, which corresponds to the values of the time at each cycle beginning.

It appears that the modulus (Fig. 8a) remains low during the early moments of cure as its value is lower than $0.05 \mathrm{MPa}$ when $\mathrm{t}<2 \mathrm{~h}$. It then rises quasi-linearly with time until reaching a value of approximately $150 \mathrm{MPa}$ at $\mathrm{t}=7.5 \mathrm{~h}$. The increase of the modulus then slows and varies linearly with time until reaching approximately $2000 \mathrm{MPa}$ at $22 \mathrm{~h}$. This rapid evolution of the modulus followed by a slower increase during the late times of cure was already observed by several authors in the literature $[1,11,22,23]$. It is attributed to the approach of the gelification of the adhesive and to the increase of the glass transition temperature which leads to a slower polymerization. The identified viscosity (Fig. 8b) is also negligible during the early moments of cure, as its value approaches $1 \mathrm{~Pa} \cdot \mathrm{s}$ at $\mathrm{t}=0 \mathrm{~h}$. It then rises exponentially with time, tending to a vertical asymptote by $\mathrm{t}=10.5 \mathrm{~h}$. The last identified values of the viscosity attain $1 \mathrm{MPa} \cdot \mathrm{s}$. This time corresponds to the gel point of the adhesive, as its behavior tends to a purely elastic one. An exponential type increase of the viscosity with time was already mentioned in previous studies $[1,22]$.

During tests, the stiffness of the bonded joint exceeds the one of the machine. Figure 9 presents the stiffness evolution over time compared to the estimated machine stiffness. The adhesive film has the same stiffness as the machine $6 \mathrm{~h}$ after its implementation, then a stiffness 10 times greater after $7 \mathrm{~h} 30$.

Secondly, since $E_{a}$ and $\eta_{a}$ are linked, if the viscosity is overestimated, as previously forebode, then the evaluation of $E_{a}$ is biased accordingly.

Table 1 gives indications from the adhesive data sheet provided by the supplier. The value of viscosity after mixing given by the supplier is consistent with the one measured by the method presented here. Indeed, it reaches $0.4 \mathrm{~Pa} \cdot \mathrm{s}$ where the developed test led to

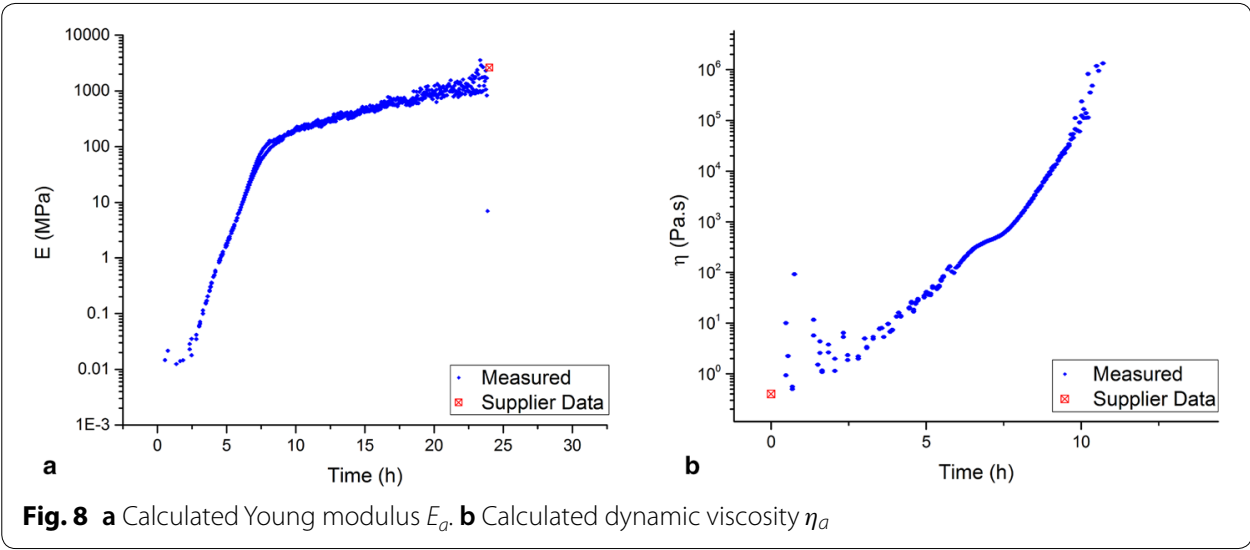




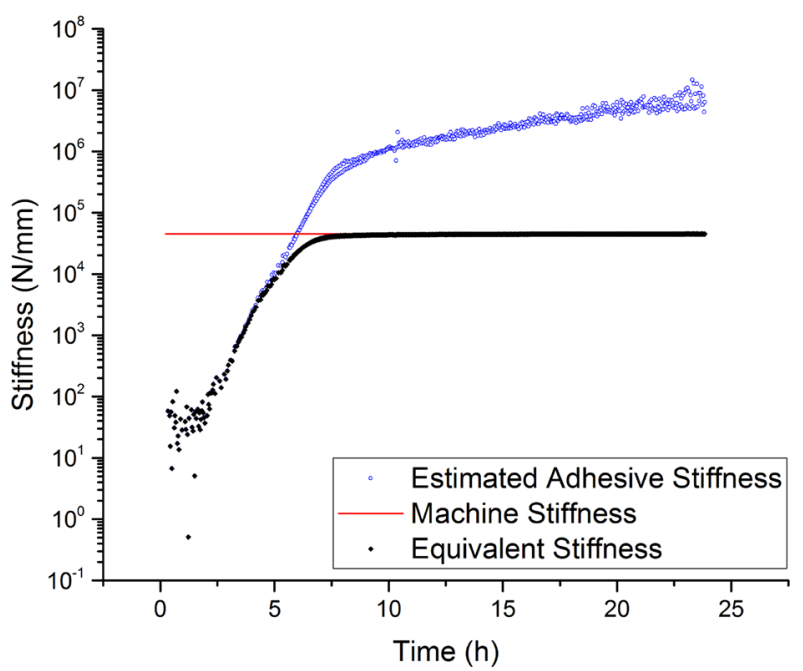

Fig. 9 Comparison of the bonded joint stiffness and the one of the machine

Table 1 Indications from adhesive data sheet

\begin{tabular}{llll}
\hline Parameters & Methods & Time after mixing & Values \\
\hline Mix viscosity at $25^{\circ} \mathrm{C}$ & BROOKFIELD LVT & $0 \mathrm{~h}$ & $400 \mathrm{mPa} \cdot \mathrm{s}$ \\
Flexural modulus at $23^{\circ} \mathrm{C}$ & ISO 178:2001 & $24 \mathrm{~h}$ & $2600 \mathrm{MPa}$ \\
\hline
\end{tabular}

an initial value of the viscosity of approximately $1 \mathrm{~Pa} \cdot \mathrm{s}$ (Fig. 8b). The values of the modulus are also in relatively good agreement (Fig. 8a), given the point of vigilance regarding the stiffness of the machine. The measured Young's modulus attains the same order of magnitude as the supplier one, after $24 \mathrm{~h}$ of cure at room temperature.

Regarding the obtained results in Fig. 8a, b, it appears the early values determined at the beginning of the cure are more altered compared to the ones obtained during cure. This is due to the sensitivity of the load cell of the test machine, which is given at $0.5 \mathrm{~N}$ by the machine supplier. As can be seen in Fig. 6a, the load variations remain low during these early moments, which leads to non-negligible uncertainties. This could be improved by reducing the sensitivity of the load cell. Also, as the chemical shrinkage is not taken into account in this model, it is not possible to estimate the evolution of the load over time. An improvement of the model would permit to describe more precisely the complete behavior of the joint during cure. These different limitations will be addressed in an upcoming study. Nevertheless, the obtained results demonstrate the ability of this simple test method to obtain the evolution of the Young's modulus and viscosity of an adhesive matrix during cure.

\section{Conclusion}

Identifying the mechanical behavior of thermosetting adhesives is of outmost importance in order to predict their initial residual stresses state and its possible impact on the bonding strength. The present study aims at presenting a simple experimental set-up and the associated analytical model to identify the visco-elastic behavior of an adhesive 
during cure. The experiment consists in a compressive test where a thin adhesive sample $(350 \mu \mathrm{m})$ is cyclically submitted to a compressive solicitation between two steel plots during cure. The whole system is mounted on a standard tensile test machine. This permits to independently identify the contribution of the viscous and the elastic behavior of the material within each cycle. The material response is modeled thanks to a Maxwell visco-elastic model, which is analytically fitted to the experimental results. This allows to identify the relative material properties, i.e. the viscosity and Young's modulus of the adhesive. This method is applied to an epoxy adhesive during cure at room temperature. The obtained viscosity and Young's modulus evolution are compared with values provided by the supplier, showing good agreement. This method therefore permits to continuously identify the mechanical behavior of a thermosetting adhesive during cure, using only one simple device (i.e. a tensile test machine) and an analytical identification method. As a consequence, it represents a good compromise between a non-accurate purely elastic approach and a complex visco-elastic identification based on a rheometer and a DMA. Even though this method relies on several hypotheses, the results obtained are consistent with those from the adhesive manufacturer's data sheet, which proves the ability of the method to describe the visco-elastic behavior of the adhesive during cure.

\section{Abbreviations}

DMA: Dynamical mechanical analysis; LVDT: Linear variable differential transformer.

Acknowledgements

Not applicable.

\section{Authors' contributions}

MG and PC designed the methodology for the parameters identification. MG implemented the tests, developed the model and its analytical analysis, and identified the required parameters. MP and MG interpreted the data and were major contributors in writing the manuscript. All authors read and approved the final manuscript.

Funding

All the actions of this study (experimental tests, establishment of the model, analysis and writing the manuscript) were carried out using the laboratory's own resources.

\section{Availability of data and materials}

The datasets used and/or analysed during the current study are available from the corresponding author on reasonable request.

\section{Competing interests}

The authors declare that they have no competing interests.

Received: 29 November 2019 Accepted: 14 February 2020

Published online: 26 February 2020

\section{References}

1. Adolf D, Chambers R. Verification of the capability for quantitative stress prediction during epoxy cure. Polymer. 1997;38:5481-90. https://doi.org/10.1016/S0032-3861(97)00077-3.

2. Courtois A, Hirsekorn M, Benavente $M$, et al. Viscoelastic behavior of an epoxy resin during cure below the glass transition temperature: characterization and modeling. J Compos Mater. 2019;53:155-71.

3. Dauvillier BS, Hübsch PF, Aarnts MP, Feilzer AJ. Modeling of viscoelastic behavior of dental chemically activated resin composites during curing. J Biomed Mater Res. 2001;58:16-26.

4. Dillard DA. Advances in structural adhesive bonding. Amsterdam: Elsevier; 2010.

5. Dixon S, Jaques D, Edwards C, Palmer SB. The development of shear and compression elastic moduli in curing epoxy adhesives measured using non-contact ultrasonic transducers. Rev Quant Nondestruct Eval. 2003;22:1049-55. https ://doi.org/10.1063/1.1570249.

6. Ernst LJ, Yang DG, Kiasat MS, Zhang GQ (2000) Determination of visco-elastic properties during the curing process of underfill materials. p.1070-1077.

7. Hossain M, Possart G, Steinmann P. A small-strain model to simulate the curing of thermosets. Comput Mech. 2009:43:769-79. https://doi.org/10.1007/s00466-008-0344-5. 
8. Johnston AA (1997) An integrated model of the development of process-induced deformation in autoclave processing of composite structures. University of British Columbia.

9. Lemaitre J, Chaboche JL. Mechanics of solid materials. Cambridge: Cambridge University Press; 1994.

10. Lin $Y$, Hwang $S$, Lee $H$, et al. Modeling of viscoelastic behavior of an epoxy molding compound during and after curing. IEEE Trans Compon Packag Manuf Technol. 2011;1:1755-60. https://doi.org/10.1109/TCPMT.2011.2165339.

11. Lindrose AM. Ultrasonic wave and moduli changes in a curing epoxy resin. Exp Mech. 1978;18:227-32. https://doi. org/10.1007/BF02328418.

12. Lopes MB, Serralvo AD, Felizardo KR, et al. Evaluation of the flexural resistance and stress contraction of a siloranebased composite submitted to different protocols of polymerization. Appl Adhes Sci. 2014;2:23. https://doi. org/10.1186/s40563-014-0023-z.

13. Moosburger-Will J, Greisel M, Sause MGR, et al. Influence of partial cross-linking degree on basic physical properties of RTM6 epoxy resin. J Appl Polym Sci. 2013;130:4338-46. https://doi.org/10.1002/app.39722.

14. Nairn JA. Energy release rate analysis for adhesive and laminate double cantilever beam specimens emphasizing the effect of residual stresses. Int J Adhes Adhes. 2000;20:59-70. https://doi.org/10.1016/S0143-7496(99)00016-0.

15. Nawab Y, Casari P, Boyard N, Jacquemin F. Characterization of the cure shrinkage, reaction kinetics, bulk modulus and thermal conductivity of thermoset resin from a single experiment. J Mater Sci. 2013;48:2394-403. https://doi. org/10.1007/s10853-012-7026-6.

16. Nawab Y, Shahid S, Boyard N, Jacquemin F. Chemical shrinkage characterization techniques for thermoset resins and associated composites. J Mater Sci. 2013;48:5387-409. https://doi.org/10.1007/s10853-013-7333-6.

17. O'Brien DJ, Mather PT, White SR. Viscoelastic properties of an epoxy resin during cure. J Compos Mater. 2001;35:883904. https://doi.org/10.1106/HLYM-5CM7-BP9N-L1Y1.

18. Öztürk B, Gromala P, Otto C, et al (2012) Characterization of adhesives and interface strength for automotive applications. In: 2012 13th international thermal, mechanical and multi-physics simulation and experiments in microelectronics and microsystems 2-5. https://doi.org/10.1109/ESimE.2012.6191807.

19. Peron M, Sobotka V, Boyard N, Le Corre S. Bulk modulus evolution of thermoset resins during crosslinking: is a direct and accurate measurement possible? J Compos Mater. 2016. https://doi.org/10.1177/0021998316647119.

20. Plepys AR, Farris RJ. Evolution of residual stresses in three-dimensionally constrained epoxy resins. Polymer. 1990;31:1932-6.

21. Presser M, Geiss PL. Experimental investigation of the influence of residual stress due to curing shrinkage on the interphase formation in adhesively bonded joints. Procedia Eng. 2011;10:2743-8. https://doi.org/10.1016/J.PROEN G.2011.04.457.

22. Puentes J, Colon Quintana JL, Chaloupka A, et al. Moduli development of epoxy adhesives during cure. Polym Test. 2019;77:105863. https://doi.org/10.1016/.jpolymertesting.2019.04.010

23. Ruiz E, Trochu F. Numerical analysis of cure temperature and internal stresses in thin and thick RTM parts. Compos Part A Appl Sci Manuf. 2005;36:806-26. https://doi.org/10.1016/j.compositesa.2004.10.021.

24. Sadeghinia M, Jansen KMB, Ernst L. Characterization and modeling the thermo-mechanical cure-dependent properties of epoxy molding compound. Int J Adhes Adhes. 2012;32:82-8. https://doi.org/10.1016/j.jjadh adh.2011.10.007.

25. Souza JPB, Reis JML. Thermal behavior of DGEBA (diglycidyl ether of bisphenol A) adhesives and its influence on the strength of joints. Appl Adhes Sci. 2013;1:6. https://doi.org/10.1186/2196-4351-1-6.

26. Yu H, Adams RD, Lucas FM. Development of a dilatometer and measurement of the shrinkage behaviour of adhesives during cure. Int J Adhes Adhes. 2013;47:26-34. https://doi.org/10.1016/j.jjadhadh.2013.09.005.

27. Zhang Y, Qin TY, Noda NA, Duan ML. Strength analysis of adhesive joints of riser pipes in deep sea environment loadings. Appl Adhes Sci. 2013;1:9. https://doi.org/10.1186/2196-4351-1-9.

\section{Publisher's Note}

Springer Nature remains neutral with regard to jurisdictional claims in published maps and institutional affiliations.

\section{Submit your manuscript to a SpringerOpen ${ }^{\circ}$ journal and benefit from:}

- Convenient online submission

- Rigorous peer review

- Open access: articles freely available online

- High visibility within the field

- Retaining the copyright to your article

Submit your next manuscript at $\boldsymbol{\nabla}$ springeropen.com 